\title{
Missed retained knife blade injury: A potentially lethal trap for the unwary
}

\author{
Victor Kong, John Bruce, Leah Naidoo, George Oosthuizen, \\ Grant Laing, Damian Clarke
}

\begin{abstract}
Introduction: Retained knife blade is an uncommon injury and they often present in a spectacular fashion. Concealed retained knife blade, however, is difficult to diagnose without a detailed clinical and radiological assessment. Extraction requires careful planning in a controlled environment, preferably in the operating theater. Case Report: We present the highly unusual case of a 25 -year-old male in whom a retained knife blade following a stab to the left anterior leg was missed on three separate visits to a rural hospital. Conclusion: Whilst diagnosis and management continues to be challenging, clinicians must always remain vigilant to the possibility of such injury. When the presentation is unclear, a high level of suspicion,
\end{abstract}

VictorKong ${ }^{1}$, JohnBruce ${ }^{2}$, LeahNaidoo ${ }^{3}$, George Oosthuizen ${ }^{4}$, Grant Laing ${ }^{2}$, Damian Clarke ${ }^{4}$

Affiliations: ${ }^{1} \mathrm{MBChB}$, Surgical Registrar, Pietermaritzburg Metropolitan Trauma Service, Department of Surgery, Edendale Hospital, Pietermaritzburg, KwaZulu Natal, South Africa; ${ }^{2} \mathrm{FCS}(\mathrm{SA})$, Consultant Trauma Surgeon, Pietermaritzburg Metropolitan Trauma Service, Department of Surgery, Edendale Hospital, Pietermaritzburg, KwaZulu Natal, South Africa; ${ }^{3} \mathrm{MBChB}$, Surgical House Officer, Pietermaritzburg Metropolitan Trauma Service, Department of Surgery, Edendale Hospital, Pietermaritzburg, KwaZulu Natal, South Africa; ${ }^{4} \mathrm{FCS}(\mathrm{SA})$, Senior Consultant Trauma Surgeon, Pietermaritzburg Metropolitan Trauma Service, Department of Surgery, Edendale Hospital, Pietermaritzburg, KwaZulu Natal, South Africa.

Corresponding Author: Victor Yeewai Kong, Pietermaritzburg Metropolitan Trauma Service, Department of Surgery, Edendale Hospital, Private Bag X509, Plessislaer, Pietermaritzburg, 3216, KwaZulu Natal, South Africa; Cell No: +27(0)797411036; Fax: +27(0)333954094; Email: victorywkong@yahoo.com

Received: 06 December 2012

Accepted: 22 May 2013

Published: 01 September 2013 careful clinical assessment and judicious use of radiography is of paramount importance. Early referral to a trauma center for definitive management is crucial.

Keywords: Missed injury, Retained knife blade, Extraction

$* * * * * * * * *$

Kong V, Bruce J, Naidoo L, Oosthuizen G, Laing G, Clarke D. Missed retained knife blade injury: A potentially lethal trap for the unwary. International Journal of Case Reports and Images 2013;4(9):507-510.

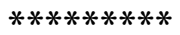

doi:10.5348/ijcri-2013-09-367-CR-11

\section{INTRODUCTION}

Knife injuries are common and can present with a full spectrum of pathology, ranging from minor cuts to severe life-threatening injuries. Retained knife blade injury logically falls within the scope of this injury spectrum [1]. Delayed presentation due to missed injuries is associated with significant morbidity [2]. We report a highly unusual case of a 25-year-old male who presented to our trauma unit some three weeks after the initial injury, with a concealed, retained knife blade in the left leg. It emerged that the actual injury was missed and he had been sent home by the doctor on multiple occasions.

\section{CASE REPORT}

Mr. B was 25-year-old male who presented to a rural hospital following a single stab injury to the left anterior leg. He was moderately intoxicated at the time. He was assessed by a locum doctor at the hospital and was thought to be an uncomplicated superficial stab wound. 
He was discharged home after being given a prescription for paracetamol. One week after his initial injury, the patient presented again complaining of increasing pain from the wound. Apart from some localized tenderness, there was no discharge or surrounding cellulitis. He was given a course of oral flucloxacllin, $250 \mathrm{mg}$, four times daily for presumable wound sepsis. He represented again the following week with no improvement and complained of a sense of fullness and increasing pain in the anterior leg extending to the calf. It was decided that antibiotics dose was to be increase and he was again discharged with a further course of oral flucloxacllin, this time at $500 \mathrm{mg}$, four times daily. A week later, he presented for the third time complaining of worsening of his symptoms, and at the patient's insistence, he was referred to our trauma unit for a second opinion.

On arrival, the patient was in significant discomfort. His baseline vitals were: heart rate: $90 / \mathrm{min}$, blood pressure: $135 / 70 \mathrm{mmHg}$, temperature $37.5^{\circ} \mathrm{C}$. A small puncture wound (approximately $1.5 \times 1.5 \mathrm{~cm}$ ) was noted in the anterior aspect of the left leg (Figures 1 and 2) and approximately $10 \mathrm{~cm}$ inferior to the tibial tuberosity. The wound edges appear sloughy, with no surrounding cellulitis. Tenderness was noted that extended from anterior leg to the calf but no foreign body was palpable. His pulses in the lower limbs were normal and equal, with normal Doppler flow signal. Suspicion was aroused about the retention of a foreign body and an urgent $\mathrm{X}$-ray was arranged. A large retained knife blade was seen, with the trajectory in the superior direction, lodged between the interosseus membrane (Figure 3). He was commenced on intravenous co-amoxiclav, $1.2 \mathrm{~g}$, and was taken immediately to the operating theatre for a planned removal. Intraoperatively, a longitudinal incision was made extending from the wound edge, and the knife blade was immediately visible. The knife blade was easily extracted with minimal hemorrhage (Figure 4). There was no evidence of osteomyelitis. An on-table angiography was performed, which showed no vessel injuries. The wound was thoroughly irrigated and was left to close by secondary intension. He had an uneventful recovery and was discharged on fifth day.

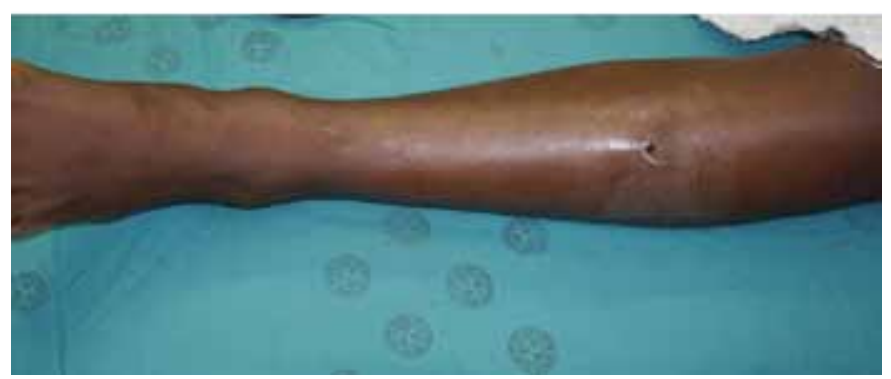

Figure 1: Stab wound on the anterior aspect of the left tibia, seen 3 weeks after the initial injury.

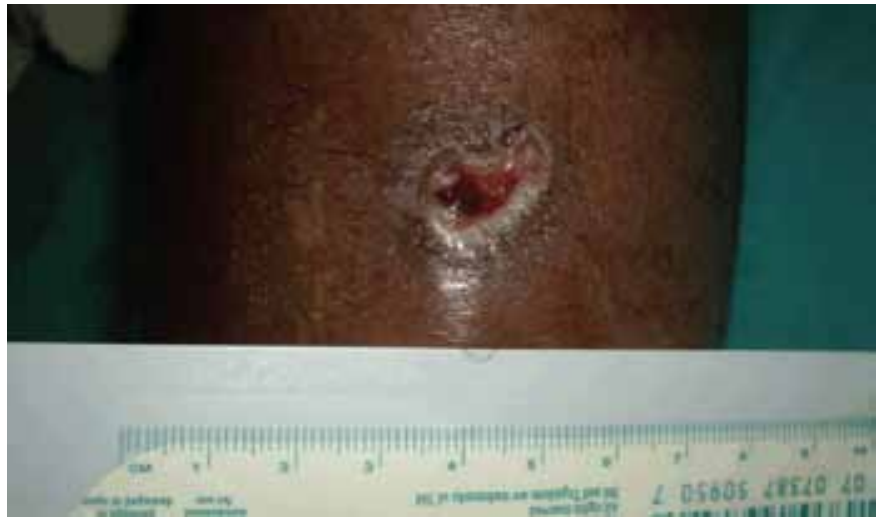

Figure 2: Approximate dimension of the wound, note the sloughy edge.

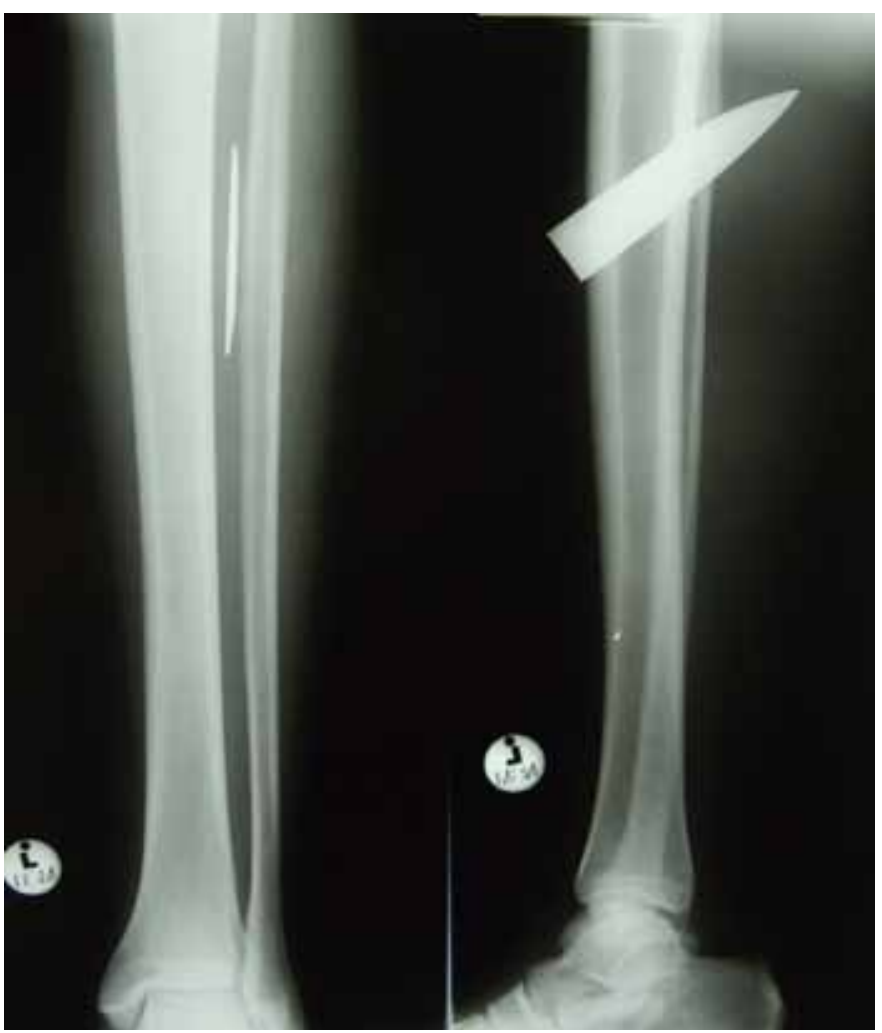

Figure 3: X-ray depicting the retained knife blade. Note the direction of the blade.

\section{DISCUSSION}

Retained knife blade remains a rather uncommon injury [1]. Most of these injuries usually present in spectacular fashion and the protruding objects are usually obviously visible $[3,4]$. Heroic attempts at extraction in the emergency department may result in massive torrential hemorrhage [5]. Most experience reported in literatures has been from isolated case reports and several small case series $[1,6,7]$. Being an uncommon injury, most centers have limited experience in its management [1]. Concealed retained knife blade injury is much more 


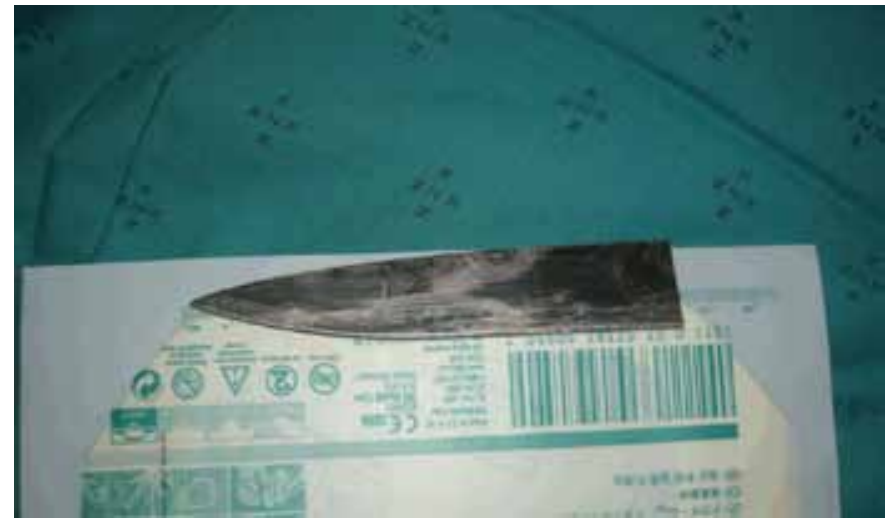

Figure 4: Extracted knife blade. The shaft had clearly broken off after the initial impact.

unusual. It becomes even more problematic if the initial retained blade is not recognized. Delayed presentation is not uncommon and one series reported a delay of up to eight weeks after the initial injury [7]. Delay can be associated with significant morbidity relating to sepsis, even more so with injuries to the extremities.

This highly unusual case highlighted several important issues worth discussing. Our patient initially presented to a rural hospital and based on an unclear history related to intoxication, the injuries was missed. However, with the subsequent multiple representations, the possibility of a retained blade injury was never considered, leading to significant further delay in diagnosis. No radiography was even taken on the suspected areas as the injury was never considered, which would have easily revealed the retained blade. In this case, the old adage of "what the mind does not know, the eyes do not see' stood the test of time.

It is equally important to recognize that the appearance of a stab wound can be deceptive. It is also obvious that it bears no relationship to the magnitude of the potential underlying injury. In our case, it was also rather peculiar having noted that the wound was only approximately $1.5 \mathrm{~cm}$, but the width of the retained blade was over $2 \mathrm{~cm}$. The most likely explanation of this disparity was probably related to a degree of wound contraction after a long delay. However, it is crucial to understand that this type of presentation could potentially be misleading.

This case, however, is not an isolated incidence related to suboptimal management for these patients who present to rural hospitals in South Africa [8]. Rural hospitals in South Africa and other developing countries, facilities and resources are often severely limited [8]. This situation is usually further compounded by a severe and on-going shortage of medical staff and poorly maintained infrastructures. The few who provide these essential health services often lack the training and experience in managing trauma patients [8]. Furthermore, even in wellstaffed urban trauma centers, diagnosis and management of these patients is still difficult.
Once the retained knife blade was identified, the issue with definitive management can be difficult. In most situations, a spiral computed tomography (CT) scan can usually help defining the relation between the retained blade and major significant anatomical structures [5]. This will generally facilitate a far safer extraction plan [1]. Angiography is generally recommended if initial CT scan is equivocal, especially if a major vascular injury is suspected [1]. In our case, we elected to pursue a combined exploration and extraction in the operating theater due to the anatomical location of the injury. It was anticipated that major hemorrhage in the vessels inferior to the arterial trifurcation of the knee could be safely dealt with and adequate vascular control achieved. Furthermore, if there were injuries to one of the small branches from the trifurcation, it was highly unlikely this would have significant impact on the lower limb perfusion, and a simple ligation would have been a safe option [9]. The subsequent on table angiogram performed proved to be reassuring. Despite the patient's protracted delayed to missed diagnosis on multiple occasions, he fortunately made a full recovery.

\section{CONCLUSION}

Retained knife blade is an uncommon injury. Concealed, retained knife blade is notoriously to diagnose. Therefore, a high index of suspicion must be maintained, coupled with judicious use of imagining, especially if the history is unclear. Early and carefully planned extraction in the operating theatre by a suitably trained trauma specialist remains the cornerstone of good management.

$$
* * * * * * * * *
$$

\section{Author Contributions}

Victor Kong - Substantial contributions to conception and design, Acquisition of data, Analysis and interpretation of data, Drafting the article, Revising it critically for important intellectual content, Final approval of the version to be published

John Bruce - Acquisition of data, Drafting the article, Revising it critically for important intellectual content, Final approval of the version to be published

Leah Naidoo - Acquisition of data, Drafting the article, Revising it critically for important intellectual content, Final approval of the version to be published

George Oosthuizen - Acquisition of data, Drafting the article, Revising it critically for important intellectual content, Final approval of the version to be published Grant Laing - Acquisition of data, Drafting the article, Revising it critically for important intellectual content, Final approval of the version to be published

Damian Clarke - Acquisition of data, Drafting the article, Revising it critically for important intellectual content, Final approval of the version to be published 


\section{Guarantor}

The corresponding author is the guarantor of submission.

\section{Conflict of Interest}

Authors declare no conflict of interest.

\section{Copyright}

(C) Victor Kong et al. 2013; This article is distributed under the terms of Creative Commons attribution 3.0 License which permits unrestricted use, distribution and reproduction in any means provided the original authors and original publisher are properly credited. (Please see www.ijcasereportsandimages.com/copyright-policy.php for more information.)

\section{REFERENCES}

1. Sobnach S, Nicol A, Nathire H, Kahn D, Navsaria P. Management of the retained knife blade. World $\mathrm{J}$ Surg 2010 Jul;34(7):1648-52.
2. Madhok BM, Roy DD, Yeluri S. Penetrating arrow injuries in Western India. Injury 2005;36(9):104550.

3. Kelly IP, Attwood SE, Quilan W, Fox MJ. The management of impalement injury. Injury 1995;26(3):191-3.

4. Thomson BN, Knight SR. Bilateral thoracoabdominal impalement: avoiding pitfalls in the management of impalement injuries. J Trauma 2000;49(6):1135-7.

5. Hanoch J, Feigin E, Pikarsky A, Kugel C, Rivkind A. Stab wound associated with terrorist attacks in Israel. JAMA 1996;276(5):388-90.

6. Grobbelaar A, Knottenbelt JD. Retained knife blades in stab wounds of the face: is simple withdrawal safe? Injury 1991;22(1):29-31.

7. van Lierop AC, Raynham O, Basson O, Lubbe DE. Retained knife blades in the ear, nose and throat: three cases. J Laryngol Otol 2009;123(3):351-5.

8. De Villiers MR, De Villiers PJT. Doctors' views of working conditions in rural hospitals in the Western Cape. SA Fam Pract 2004;46(3):21-6.

9. Ballard JL, Bunt TJ, Malone JM. Management of small artery vascular trauma. Am J Surg 1992;164(4):316-9.
Access full text article on other devices

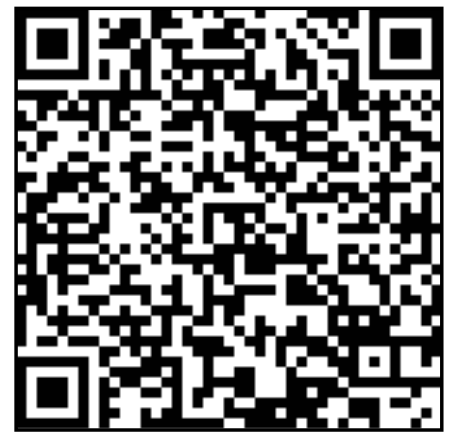

Access PDF of article on other devices

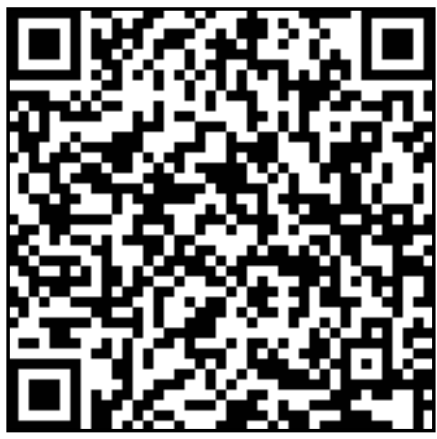

